\title{
An Experimental Study on the Effect of Additives on Solidified Performance of Sediment
}

\author{
Hui Zhang, Jianzhong Zhu, LingCheng Hong, HaiBo Shi, MinXia He \\ Key Laboratory of Integrated Regulation and Resource Development on Shallow Lake of Ministry of Education, College \\ of Environment, Hohai University, Nanjing 210098, China \\ 1546401431@qq.com \\ zhuhhai2010@hhu.edu.cn \\ Corresponding author: Jianzhong Zhu
}

\begin{abstract}
Using dredged sediments as construction materials can alleviate the problem of sediment disposing, while properties have to be improved for corrosive environment. The effectiveness of using sodium bentonite and agent $\mathbf{J}$ (home-made agent) was investigated by means of laboratory tests to evaluate the compatibility of solidified sediment cubes in corrosive environment. Cube crushing strength (CCS) and water immersion tests were carried out. After curing the sediment, the undefined compressive strength of samples achieved $165 \%$ improvement after 7 days. The strength loss rate significantly dropped by $\mathbf{2 8 . 5 \%}$ and $18.8 \%$ in acid or saline solution respectively. Therefore, this technique is worth popularizing for solidified performance improvement.
\end{abstract}

Keywords-Curing;agent;sodium;bentonite;corrosion;resist ance; unconfined compressive strength;strength loss rate

\section{I . INTRODUCTION}

Dredging operation in China has been generating a considerable amount of sediment year after year.Generally, the dredged sediments are extremely soft soils with such poor geotechnical properties [1]that they cannot be directly used in construction.Traditional techniques of disposing dredged sediments may cause significant damage to the environment due to nutrition and heavy metals contained in dredged sediments[2]. Chemical solidification technology is widely used in improving the mechanical and environmentally friendly properties of sediments by using cement, sodium bentonite and other binders[3-6]. With cement added, water in dredged sediments chemically reacts with cement, thus forms hydrated silicates and aluminates resulting in a solid monolithic mass[7]. In addition, sodium bentonite can absorb kinds of gas, liquid and organic matter and has the potential of plasticity and cohesiveness, which is also proved to improve the properties of sediment. The current study focuses on the effect of binders including cement-based materials, sodium bentonite, agent J(home-made material) and $\mathrm{NaOH}$ and studies the corrosion resistance of the solidified sediment. The objectives of this study are to:(1) investigate the effect of each binder in treated sediments and testify the high efficiency of variable materials,(2)analyze the durability and corrosion resistance of solidified sediments through water immersion test,(3) find out difference between several results of solidification.

\section{II . MATERIALS AND METHODS}

\section{A. Materials and mix proportions}

In this study the dredged sediments were taken from the bottom of Qinhuai River in Nanjing. Basic physical index tests were conducted in accordance with the procedures given in GB/T 50123-1999 [8].

The binders included cement-based materials, sodium bentonite, agent J. Cement-based materials included Portland cement, fly ash, phosphogypsum.In order to improve the properties of the materials,three groups of mixes were designed.A compound experiment (group C) was carried out especially,involving sodium bentonite and agent J.The specific dosage of sodium bentonite,agent $\mathrm{J}$ would be determined by further experiment.

\section{B.Experimental methods}

To evaluate the mechanical and durability properties of designed mixes, cube crushing strength (CCS) test were carried out according to Standard for Test Method of Performance on Building Mortar (JGJ/T70-2009)[9].All standard samples sized $70.7 \mathrm{~mm} \times 70.7 \mathrm{~mm} \times 70.7 \mathrm{~mm}$ were cured in sealed plastic boxes for 7 and 28 days at a room temperature. All CCS measurements presented here were the three measured values and their average value. To evaluate the corrosion resistance of designed mixes,the compacted samples in standard mold were subjected to water immersion and then taken to CCS tests as above[10].

\section{RESULTS AND DISCUSSION}

\section{A. Influence of binders on cube strength of concrete mixtures}

a) Influence of agent J:Comparing with No.0 tested independently, the strength of group A achieved a large growth. According to the tendency viewed in the Figure 
1(a),the unconfined compressive strength after 7 days and 28 days both increased firstly and then declined with the variable materials amount increasing. And A3,the one added $1.3 \%$ agent $\mathrm{J}$, achieved the optimum unconfined compressive strength-4.53MPa for 28 days. Figure 1(b) presents that the strength appeared to increase just slightly and then declined when adding agent J. The best flexural strength was achieved at A3, which was similar with the conclusion above.

b) Influence of sodium bentonite:The unconfined compressive strength achieved $165 \%$ and 59\% improvement respectively for 7 and 28 days.This indicated that casodium bentonite can obviously improve the strength in alkaline environment.The optimum effect appeared at the point B3,containing 3.2\% casodium bentonite(Figure 2(a)).Figure 2(b) shows that there was no apparent difference between No.0 and group A for flexual strength, while the sample B3 reached the optimum in group B .

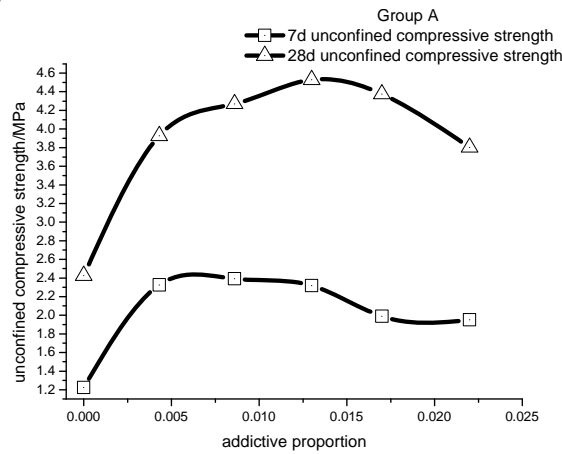

(a)

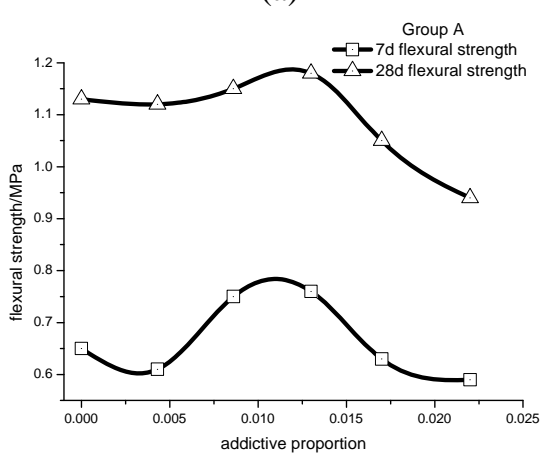

(b)

Figure 1. Strength of group A a:unconfined compressive strength;b:flexural strength

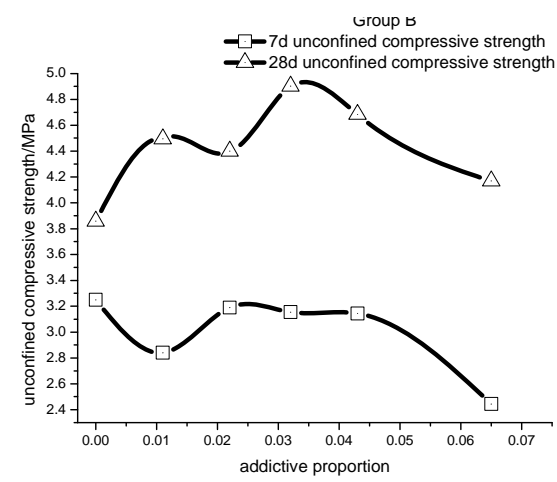

(a)

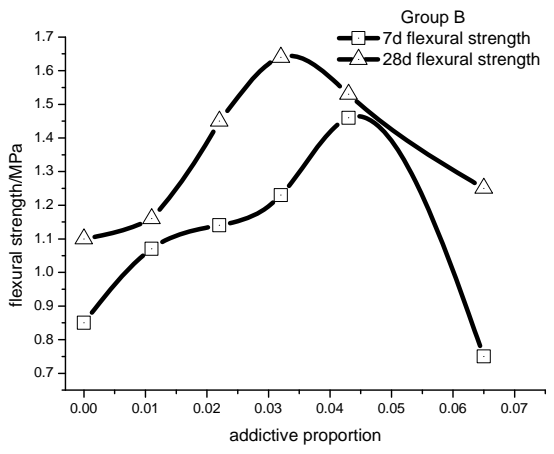

(b)

Figure 2. Strength of group B a:unconfined compressive strength;b:flexural strength

c) Influence of sodium bentonite and agent J:Take the $7 \mathrm{~d}$ optimum points in group A and B together to carry out the compound test(represented by group C).The unconfined compressive strength got a $26.9 \%$ growth and the flexual strength increased for $6.89 \%$ after maintaining for 28 days,which achieved a little,but not significant improvement.

\section{B. Influence of binders on cube strength in corrosive environment}

In order to study the corrosion resistance of the solidified sediment, every sample had four same cubes and was immersed in four kinds of corrosive solution respectively for 7 days after maintaining for 28 days.

a) Influence of agent $J$ : The strength of cubes would still keep increasing in the later seven days when they were exposed to the atmosphere.A growth of $18.2 \%$ was achieved, though the rising trend was very slight.Cubes in water got a $3.62 \%$ increase comparing to $28 \mathrm{~d}$ maintainance,whereas lost $12.4 \%$ in unconfined compressive strength comparing with those in atmosphere,with those in hydrogen nitrate $(\mathrm{pH}=2)$ losing $24.0 \%$ and those in saturated sodium sulfate losing $21.1 \%$.

Comparing to those in the atmosphere,No.0 lost 37.9\% in hydrogen nitrate $(\mathrm{pH}=2)$ and lost $31.4 \%$ in saturated sodium sulfate in strength.The result shows that acid solution is more powerful and corrosive than saline solution to curing sediment corrosion.For group A,immersion in acid solution made a $14.1 \%$ decrease and $10.3 \%$ decrease in saline solution in strength loss rate,indicating the agent J's potential of corrosion resistance to acid and saline solution.

b) Influence of sodium bentonite:The strength of group B obtained a $17.0 \%$ increase, reflecting that cubes kept strengthening slowly after the 28 days' maintainance (Figure 3). Strength of cubes in water increased slightly and came out to lose $9.3 \%$ comparing to those in atmosphere. Cubes lost $9.4 \%$ in hydrogen nitrate $(\mathrm{pH}=2)$ and lost $12.6 \%$ in saturated sodium sulfate.The strength loss after acid immersion would drop by $28.5 \%$ comparing to No.0 and $18.8 \%$ after saline immersion,which suggested that adding sodium bentonite produced a better resistance to acid corrosion than saline corrosion. 


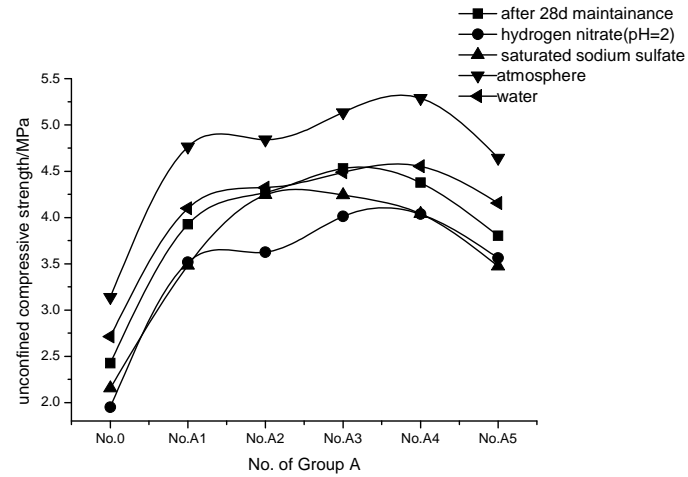

(a)

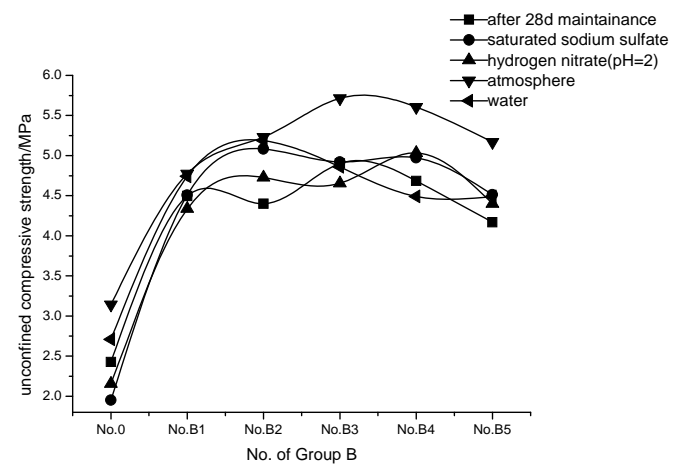

(b)

Figure 3. Unconfined compressive strength in corrosive environment a:group A;b:group B

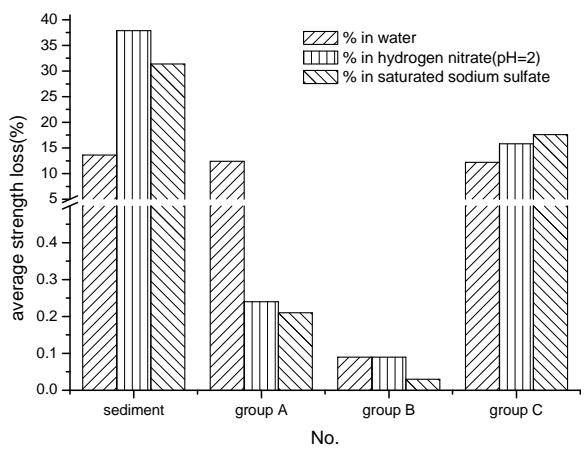

Figure 4 .Comparison of strength loss in different corrosive environment

c)Influence of sodium bentonite and agent $\mathrm{J}$ :With the combination of sodium bentonite and agent $\mathrm{J}$ added,the strength loss rate was $15.8 \%$ in hydrogen nitrate $(\mathrm{pH}=2)$ and $17.6 \%$ in saturated sodium sulfate.The result showed that the corrosion resistance was inferior to that of samples adding sodium bentonite solely,which was far from expection.

\section{IV.CONCLUSION}

(1)As variable materials agent $\mathrm{J}$ added,the strength loss decreased $14.1 \%$ and $10.3 \%$ respectively in acid or saline immersion.As variable materials sodium bentonite added,the strength loss significantly dropped by $28.5 \%$ and $18.8 \%$ in acid or saline solution respectively.The results suggested that additives could remarkably improve the corrosion resistance.
(2)Cubes which produced according to the amount of variable materials under 7 days' optimum strength,obtained a slightly improvement(about $6.89 \%$ ) in unconfined compressive strength,though not apparently comparing to two situations above.The flexual strength loss was less than the average value of cubes added agent $\mathrm{J}$ solely, while more than the average value of the ones added sodium bentonite solely.This suggested that the corrosion resistance cannot be calculated by adding together simply.

\section{ACKNOWLEDGMENT}

Financial support for this research was provided by the Scientific Research Starting Foundation for Returned Over seas Chinese Scholars, Ministry of Education, China(Grant No. 1061-51200312), the National Key Scientific Instrum ent and Equipment Development Project(Grant No. 2014Y Q060773),

the General Program (Key Program) of National Natural Science Foundation of China (Grant No.51438006), and the Priority Academic Program Development of Jiangsu Higher Education Institutions(PAPD).

This work also supported by Water Conservancy Research Funds, Jiangsu,"Study on the ecological rehabilitation tech nologies of the Creeks" (1061-51146012).

\section{REFERENCES}

[1] Huang Y.H., Zhu W., Qian X.D., Zhang N. and Zhou X.Z., Change of mechanical behavior between solidified and remolded solidified dredged materials. Eng Geol, 119, 112-119 (2011).

[2] Zentar R., Dubois V. and Abriak N.E., Mechanical behaviour and environmental impacts of a test road built with marine dredged sediments. Resources, Conservation and Recycling, 52, 947-954 (2008).

[3] Qiao X.C., Poon C.S. and Cheeseman C.R., Investigation into the stabilization/solidification performance of Portland cement through cement clinker phases. J Hazard Mater, 139, 238-243 (2007).

[4] Guha B., Hills C.D., Carey P.J. and Macleod C.L., Leaching of mercury from carbonated and non-carbonated cement-solidified dredged sediments. Soil Sediment Contaminant, 15, 621-635 (2006).

[5] Dang T.A., Kamali-Bernard S. and Prince W.A., Design of new blended cement based on marine dredged sediment. Construction Build Mater, 41, 602-611 (2013).

[6] Sparrevik M., Eek E. and Grini R.S., The importance of sulphide binding for leaching of heavy metals from contaminated Norwegian marine sediments treated by stabilization/solidification. Environment Technology, 30, 831-840 (2009).

[7] Patel H. and Pandey S., Evaluation of physical stability and leachability of Portland Pozzolona Cement (PPC) solidified chemical sludge generated from textile wastewater treatment plants. J Hazard Mater, 207-208, 56-64 (2012).

[8] GB/T 50123, Standard for soil test method, Ministry of Construction. P.R. China, Beijing (1999).

[9] JGJ/T70-2009, Standard for test method of performance on building mortar. Shanxi Institute of Building Science (2009).

[10]Navi.Three dimension characteristics of the pore structure of stimulated cement.J Cement and Concrete Research,29(4),507-514(1999). 